\section{The view from the top}

\section{Washington}

JUDGING from their first few weeks of work, researchers at the Smithsonian Tropical Research Institute are confident that the tower crane they have set up in Panama can conquer tropical ecology's last frontier - the tree canopy where most of the photosynthesis takes place and a diverse community of largely unstudied plants and animals lives.

The experimental crane is not actually in the midst of the jungle, as might appear from the picture here, but in a small (200 hectare) medium-age forest in Panama City's Metropolitan Nature Park. Nor does the crane belong to the Smithsonian; it has been rented until next April from a Panama City contractor. But once researchers are satisfied that the crane can AIDS

\section{Commission grows angrier}

\section{Washington}

OVER-rigid ground rules for participation in clinical trials of AIDS patients are excluding large segments of the infected community, including blacks, women, children and drug users, a US congressional advisory panel concluded last week. The National Commission on AIDS, in its third and hardest-hitting report to the president, said that the 12,000 people participating in AIDS trials reflect a "pitifully small" fraction of the those eligible. Blacks and Hispanics account for about 43 per cent of all AIDS cases, but only 23 per cent of the clinical trial populations, the panel noted.

The panel also criticized the National Institutes of Health (NIH) for delay in expanding their research to include opportunistic infections, the leading cause of death for people with AIDS. It noted that although $\$ 428$ million has been spent by the US AIDS Clinical Trial Programme, most approved drugs for AIDS and AIDSrelated infections have been developed outside the programme. NIH officials say efforts are being made to increase minority participation in clinical trials and the research emphasis on opportunistic infections.

Other concerns included the increasing incidence of AIDS in rural communities. In one year, there has been a 37 per cent increase in reported AIDS cases in rural areas compared with a 5 per cent rise in metropolitan areas. The panel attributes much of the growth in rural cases, especially among heterosexual women, to "the combination of crack cocaine, trading sex with multiple partners for drugs or money, and the rising rate of syphilitic infections". Christopher Anderson provide secure and repeated access to the forest canopy anywhere within reach of its 36 metres span, they hope that they will be able to persuade the US Congress to provide funds to buy and set up a larger crane at their main Panamanian research site on Barro Colorado Island.

insect diversity are under way. A key part of future projects will be to see how rates of photosynthesis are affected by the changes that might occur as greenhouse gases build up and global warming occurs; without this information it will be very hard to predict how climate change will affect tropical forests.

Smith believes the crane will provide more convenient access to the canopy

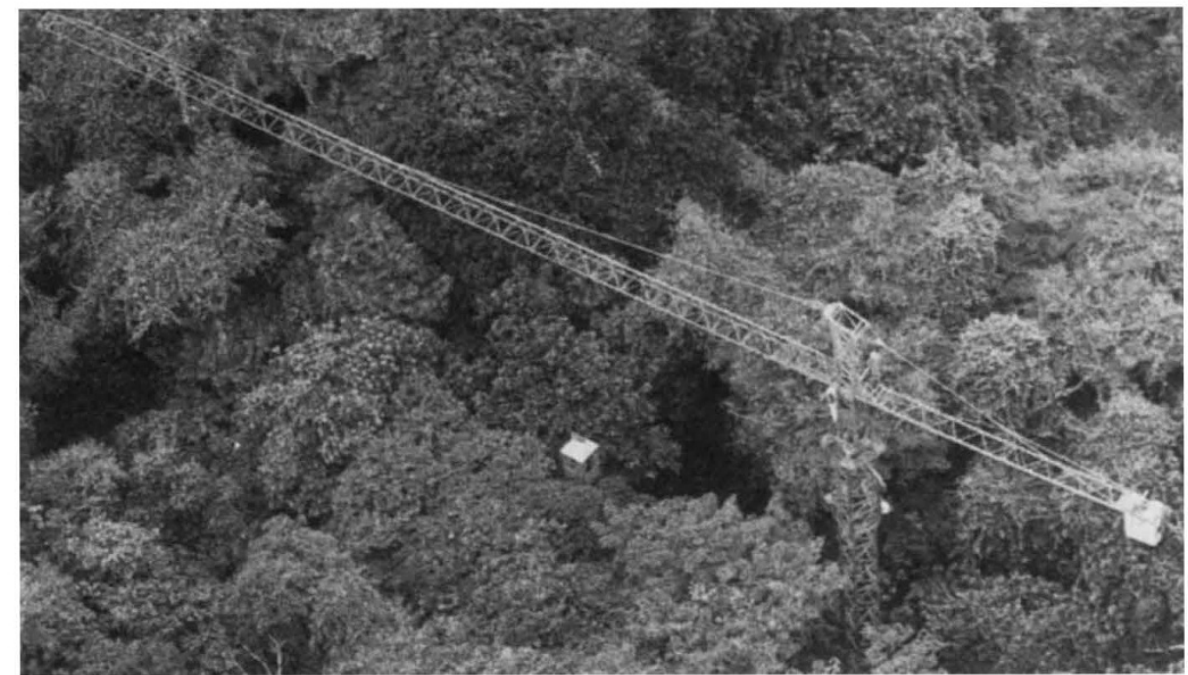

Treetop laboratory - experimental crane for gathering data in tropical forests.

Alan Smith, assistant director for terrestrial Research at the Smithsonian Tropical Research Institute, who heads the crane project, says his team is "delighted at the rate at which we are getting data, and the diversity of the data". Researchers ride in a special gondola which delivers them to any designated point in the canopy. Once there, they hook onto a branch to stop the gondola swaying too much, and get down to observations. Studies of photosynthesis, transpiration and ies of photosynthesis, transpir
ACADEMIC INSTITUTIONS

\title{
Thanks, but no thanks for impact theories
}

\section{Washington}

Allan Kelly, an 89-year-old California cattle rancher who believes that asteroid impacts are responsible for the Earth's tilt, the end of the last Ice Age and the biblical flood, has had some trouble in persuading the scientific community to see things his way. So earlier this year he offered California State University at San Marcos (CSU) \$250,000 to set up an endowed chair for a geologist to research his theories for him. According to the proposed agreement, the scientist who holds the position will "study . . . the truth and falsity of $\mathrm{Mr}$ Kelly's theories", reporting back to Kelly annually on the progress of the research.

The offer stipulates that the chair holder be named the "premier professor" of arts and sciences at the university.

On 28 August, CSU accepted the offer. University president William Stacy told the Los Angeles Times that the agreement than the time-consuming and dangerous systems of towers and aerial ropeways now in use. One earlier concern seems to have been unfounded: operation of the crane does not appear to disturb animals in the region. If the Smithsonian gets its own crane next year, it will be moved from one location to another by helicopter so that no damage is done on the ground. A crane with an 80-metre arm is favoured that will give access to five hectares of forest canopy. Alun Anderson protected the academic freedom of the chair-holder, while also giving Kelly "some reasonable assurance that the matters of special concern will receive scientific consideration". But the next day, after the Los Angeles Times published an article predicting ridicule and quoting geologists who said that no serious scientist would take the chair, the university quickly reversed its decision and returned the money to Kelly.

Although university geologists were not opposed to an endowed chair in the general area of impact theory, they were appalled that CSU would allow a donor to dictate the specific details of the research. After seeing the Times article last week, Stacy decided that other faculty members would probably feel the same way. "It's crucial to avoid any further embarrassment to the university", he said in announcing the hasty change in plans.

Christopher Anderson 